\title{
Julio De Zan 1940-2017
}

El 18 de agosto de 2017, a la edad de 76 años, falleció el Dr. Julio De Zan, miembro fundador y director de esta revista desde su creación hasta el año 2009.

Licenciado en Filosofía por la Universidad Católica Argentina y Doctor en Filosofía por la Universidad del Salvador, Julio también hizo estudios en Alemania como becario de la Fundación Alexander von Humboldt en la Universidad Ruhr de Bochum, bajo la dirección del Prof. Dr. Otto Pöggeler, y de la Fundación para el Intercambio Cultural Alemán Latinoamericano en la Universidad de Frankfurt, donde tuvo como profesores, entre otros, a Karl Otto Apel y Jürgen Habermas. Fue asimismo Investigador Principal del CONICET y Profesor Titular Ordinario en la Universidad Nacional de Entre Ríos y en la Universidad Nacional de General San Martín.

Integró numerosas asociaciones académicas nacionales e internacionales. Así, por ejemplo, fue miembro del Consejo Asesor de Cuadernos de Ética (Asociación Argentina de Investigaciones Éticas), de Cuadernos del Sur (Universidad Nacional del Sur), de Erasmus. Revista para el diálogo intercultural (Fundación para el Intercambio Cultural Alemán Latinoamericano), de Perspectivas metodológicas, (Universidad Nacional de Lanús), y del Comité Internacional del Jahrbuch für Hegelforschung (Bochum, Alemania). Sus cargos de gestión fueron también numerosos, destacándose entre ellos el de Secretario de Cultura y Comunicación social de la Provincia de Santa Fe entre 1988 y 1991 y el de Vicerrector de la Universidad Católica de Santa Fe entre 1992 y 1995. En virtud de esa extensa y destacada trayectoria, recibió el premio Konex de Humanidades en 1996 y fue declarado "Santafesino Ilustre" por el Consejo Municipal de la ciudad de Santa Fe en 2009.

Respecto de sus trabajos académicos, se concentraron en temas de ética y filosofía política, con especial atención a la filosofía alemana moderna y contemporánea y a la problemática del pensamiento latinoamericano y argentino. En tal sentido, sus libros principales son: Hacia una filosofía de la liberación latinoamericana (en colaboración) Buenos Aires, 1973; El conocimiento del 
ser y la metafísica, Santa Fe, 1985; Ética comunicativa y democracia (en colaboración), Barcelona, 1991; Libertad, poder y discurso, Buenos Aires, 1993; Éticas del siglo (en colaboración), Rosario, 1994; Panorama de la ética continental contemporánea, Madrid, 2002; La filosofía práctica de Hegel, Río Cuarto, 2003; La ética, los derechos y la justicia, Montevideo, 2004; Ética del discurso. Recepción y crítica desde América Latina (en colaboración), Río Cuarto, 2008; Los sujetos de la política en la filosofía moderna y contemporánea (en colaboración), Buenos Aires, 2008; La filosofía socialy política de Hegel, Buenos Aires, 2009; La vieja y la nueva política. Libertad, poder y discurso, Buenos Aires, 2013; La gramática profunda del ethos. Estudios sobre la filosofía moral de Kant, Buenos Aires, 2013; y La primera filosofía del espiritu de Hegel. Jena 1803/04 (traducción, introducción, notas y estudios anexos), Buenos Aires, 2016.

Trabajó hasta sus últimos días, dándonos a todos un ejemplo de entereza moral inolvidable. Fue un amigo, fue un maestro. Tópicos no será lo mismo tras su partida, pero trataremos de ser dignos de su enorme esfuerzo para que esta revista siga creciendo hasta hacerse un punto de referencia en el panorama filosófico de nuestra región y de nuestro país.

Que descanse en paz, querido Julio...

Fernando Bahr 